\title{
Gestión y liderazgo del talento: las claves del éxito empresarial
}

\section{Management and leadership talent: the keys to business success}

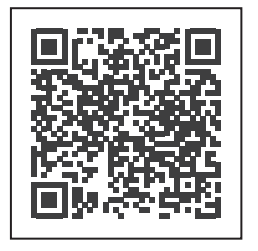

\section{Palabras clave:}

Talento humano, Capital humano, personas, organizaciones.

\section{Editorial}

Fecha de recepción: 09/06/2021

Fecha de aprobación: 15/06/2021

Esta publicación se encuentra bajo licencia:

Creative Commons Reconocimiento-NoComercial-SinObraDerivada 4.0 Internacional

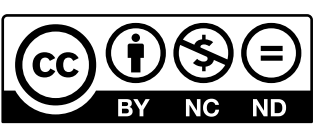

Roberto Luna-Arocas ${ }^{1}$

\section{Introducción}

Desde hace ya unas décadas, se está trabajando con profundidad en la investigación científica sobre la evidencia en las empresas de la gestión del talento. A nivel profesional, ya han sido muchas organizaciones las que han dado el salto cualitativo hacia una nueva manera de enfocar los recursos humanos (RR. HH.). Principalmente porque esta nueva perspectiva está más vinculada tanto al negocio como a los objetivos empresariales, además de ser más aceptada por la mayoría de los profesionales.

Desde los orígenes de la guerra del talento por Mckinsey hasta la actualidad, la investigación está analizando el papel de la gestión del talento en los resultados organizativos. En este sentido, Luna (2018) diseñó un modelo de gestión del talento basado en siete variables: el modelo 7GT. Este modelo contiene tres variables sistémicas que afectan a toda la organización y cuatro variables estratégicas, y aparte de implementarse en muchas organizaciones, está siendo también investigado científicamente. Del mismo modo, Luna (2021) se dio cuenta de que de nada serviría formular una nueva manera de dirigir personas basada en el talento si no se daba un cambio en el liderazgo de gran parte de las organizaciones. Por eso mismo, diseñó un modelo de seis variables para liderar desde el talento.

Doctor en Psicología Social. Catedrático de Dirección de Empresas \& Gestión del Talento, Universidad de Valencia. roberto.Iuna@uv.es, ORCID: https://orcid.org/0000-0002-6149-8944 


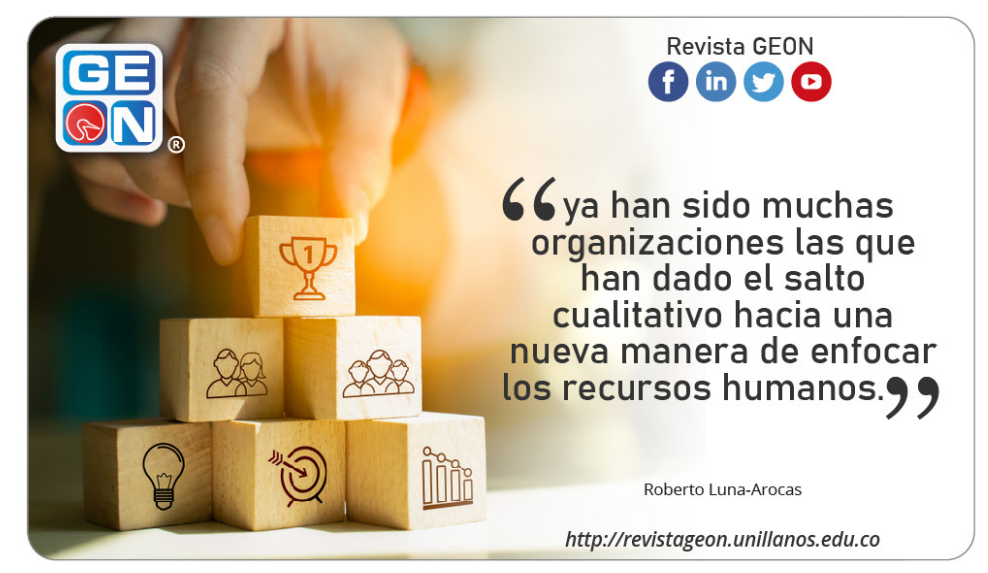

Se analizan las implicaciones de ambos modelos en el mundo organizativo y empresarial, así como se profundiza en las variables que lo componen.

Palabras Clave: Talento humano, Capital humano, personas, organizaciones

\section{Introduction}

For a few decades now, work has been done in depth on scientific research on evidence in talent management companies. At a professional level, there have already been many organizations that have made the qualitative leap towards a new way of approaching human resources (HR). Mainly because this new perspective is more linked to both business and business objectives, as well as being more accepted by most professionals.

From the origins of the Mckinsey War for Talent to the present, research is looking at the role of talent management in organizational results. In this sense, Luna (2018) designed a talent management model based on seven variables: the 7GT model. This model contains three systemic variables that control the entire organization and four strategic variables, and in addition to being implemented in many orga-

nizations, it is also being scientifically investigated. In the same way, Luna (2021) realized that it would be useless to formulate a new way of managing people based on talent if there was no change in the leadership of a large part of the organizations. 
Cómo citar este artículo /

Toreference this article:

Luna-Arocas, R. (2021). Gestión y liderazgo del talento: las claves del éxito empresarial. Revista GEON (Gestión, Organizaciones Y Negocios), 8(1), e-512. https://doi. org/10.22579/23463910.512
For this reason, he designed a six-variable model to lead from talent.

The implications of both models in the organizational and business world are analyzed, as well as the variables that compose it.

Keywords: Human talent, human capital, people, organizations

\section{El modelo 7GT de gestión del talento}

Bajo el modelo 7GT podemos encontrarnos dos tipos de variables: las sistémicas, que afectan a toda la organización, y las estratégicas, que afectan al área de RR. HH. Este modelo estructura la formulación de cualquier estrategia de gestión del talento en siete variables que pasamos a detallar a continuación.

\section{Variables sistémicas}

Tres variables componen las variables sistémicas: marca del empleador y del profesional, sistemas de compensación total y gestión del talento inteligente.

La marca del empleador se ha convertido en un área de reciente interés por su gran impacto a nivel organizativo y social, pues genera muchas sinergias positivas dentro de la organización. Conseguir ser referentes como empresa a nivel social implica que no solo hablen bien de ti los empleados, sino también los que ya no son empleados, pero lo fueron (embajadores de marca) e incluso que se tenga una buena percepción por posibles candidatos. Esta notoriedad se vincula mucho a la capacidad de generar marcas profesionales también dentro de la propia organización. De este modo, la marca profesional alimenta también la marca de empleador.

El sistema de compensación total parte de asumir que los sistemas de incentivación pueden ser tanto monetarios o financieros como no monetarios o no financieros. Como se suele decir, es intentar ir más allá de donde no llega el propio dinero. Y es que el dinero es un sistema motivacional algo limitado, que en niveles más bajos genera satisfacción e incluso algo de compromiso, pero que conforme avanza la carrera profesional pierde poder motivacional, sobre todo a nivel intrínseco. Por ello, los sistemas de compensación incorporan muchas más variables de las que denominamos "salario emocional" y que tienen que ver tanto con aspectos del puesto concretamente y sus condiciones como con el equilibrio y la conciliación entre la vida y el trabajo que permitimos a los empleados. Cuanto más complejo es el sistema 
de compensación y más variables no financieras intervienen, mayor será el impacto organizativo. Muchas organizaciones tienen que dar ya el salto de pasar de los sistemas financieros en exclusiva a ampliar su perspectiva de la compensación.

Por último, la gestión del talento inteligente es una confluencia entre la gestión del talento y la gestión del conocimiento. Esta variable implica toda información que se convierte en conocimiento dentro de la organización como ventaja competitiva y conlleva el análisis de cómo se comparte ese conocimiento para que toda la organización pueda beneficiarse de él. Por lo tanto, intervienen todos los sistemas de desarrollo del rendimiento como superación de la evaluación del rendimiento, todo el proceso de feedback y feedforward, así como los procesos de digitalización que permiten que el conocimiento fluya de modo rápido, ágil y eficiente (figura 1).

Figura 1. Variables sistémicas del modelo 7GT.

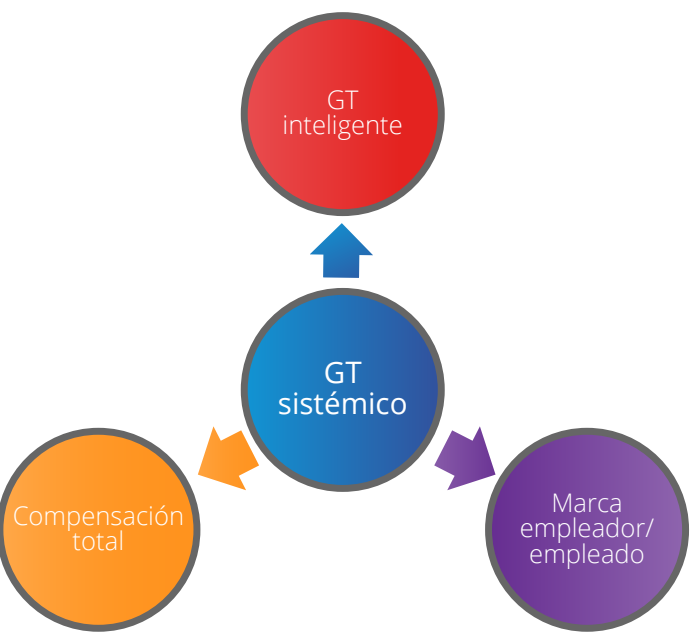

\section{Variables estratégicas}

Cuatro variables componen las principales estrategias que deben llevarse a cabo en la gestión del talento y que, de modo claro y directo, se relacionan con las tres variables previamente analizadas en el planteamiento sistémico.

De hecho, las variables estratégicas tienen un impacto claro en las tres variables anteriormente analizadas, como veremos a continuación.

Las cuatro variables son: atracción de talento, desarrollo de talento, fidelización de talento y salida de talento. La utilización adecuada de estas estrategias permite un nivel tan alto de interacción entre ellas y con las variables sistémicas, que conforma un modelo muy potente a nivel organizativo.

La atracción de talento es el proceso de entrada de personas que interesan a la organización tanto para su presente como para su futuro inmediato. Una característica muy importante de esta estrategia es que, si se ha trabajado bien las tres variables sistémicas, el proceso de atracción es muy fluido. Una persona con talento querrá entrar en nuestra organización si la contempla como buena empleadora y como una organización donde puede seguir creciendo su marca profesional. Esto permitirá que en su proceso de onboarding se analice su grado de satisfacción con la entrada a la organización y el cumplimiento de sus expectativas.

Así mismo, esta persona verá la gran potencialidad que tiene en la organi- 
zación para desarrollarse tanto por los sistemas de reskilling y upskilling y estará interesada en participar en las técnicas del desarrollo mix: coaching ejecutivo, elearning, mentoring y outdoor training.

Del mismo modo, la organización que ha atraído y desarrollado el talento no se puede permitir el lujo de perder a los empleados en el proceso, de ahí la importancia de los sistemas de fidelización que analizan la experiencia del empleado (EX), la propuesta de valor del empleado (PVE), el compromiso y el engagement del empleado, así como los programas de bienestar y gestión de la diversidad (figura 2).

Figura 2. Variables estratégicas del modelo 7GT.

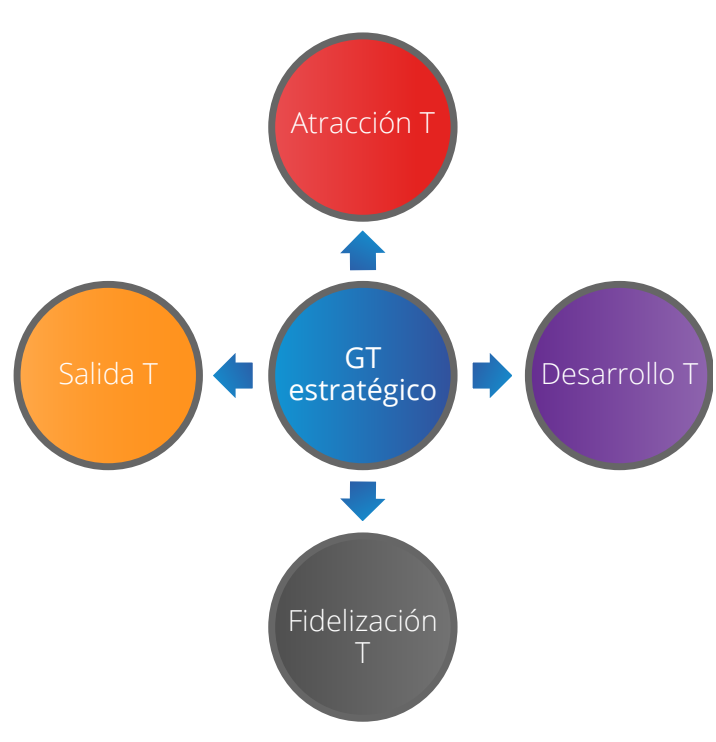

\section{Un nuevo liderazgo desde el talento}

Uno de los grandes problemas que se ha descubierto a nivel científico y profesional en los sistemas de dirección de personas es la complejidad de lo que se ha formulado por la dirección implementarlo con los equipos profesionales. Esta implementación está vinculada a dos elementos muy importantes: la cultura organizativa y el liderazgo.

Desde la cultura organizativa, la gestión del talento plantea que toda persona en la organización participe de los resultados organizativos. Eso sí, siempre y cuando haya una meritocracia que garantice el respeto por el talento y la equidad en los procesos organizativos.

Desde el liderazgo, muchas voces claman la baja calidad directiva y la complejidad de encontrar un modelo que sea capaz de dar respuesta a la baja implicación de los empleados en los proyectos organizativos.

Por ello, Luna (2021) planteó un modelo capaz de implementarse en todo tipo de organizaciones, bien sean pequeñas, medianas o grandes, y en todo tipo de sectores. Este modelo se basa en seis variables que se convierten en una guía para todo líder sobre su estilo de dirección y el grado en que está consiguiendo impactar e influir en sus colaboradores (figura 3).

Como indica el autor, los líderes deben dar respuesta a estas seis variables para poder conseguir el liderazgo desde el talento. Con que falle una de ellas, el impacto se vería seriamente reducido; por lo tanto, es un planteamiento que exige el cumplimiento de las seis variables y su aplicación real en la organización. 
Figura 3. Liderazgo desde el talento.

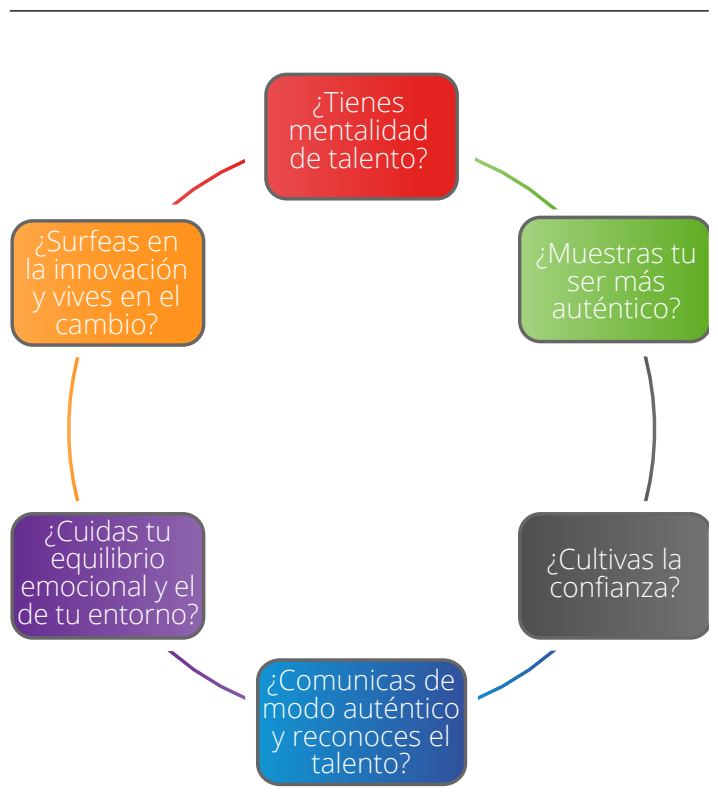

Vamos a plantear las seis variables como seis preguntas de reflexión que todo líder debería hacerse en su propio desarrollo profesional:

1. ¿Tienes como líder mentalidad de talento y sabes, por lo tanto, valorar a las personas que aportan a la organización desde la meritocracia y la equidad?

2. ¿Muestras como líder tu lado más auténtico como persona con tu autoconocimiento, dando tiempo de calidad a los demás e implicándote en proyectos realmente de impacto en tu vida profesional?

3. ¿Cultivas como líder la confianza desde la humildad y la aceptación del otro en su diversidad, así como mostrando autoconfianza y sabiendo delegar?
4. ¿Comunicas de modo auténtico y reconoces el trabajo bien hecho de modo espontáneo y natural, tanto en los procesos de feedback como en el seguimiento de los objetivos futuros mediante el coaching ejecutivo y feedforward?

5. ¿Cuidas tu equilibrio emocional y el de tu entorno laboral mostrando empatía y liderando emocionalmente desde el conocimiento de tus patrones emocionales?

6. ¿Surfeas en la innovación y vives en el cambio afrontando con naturalidad nuevas experiencias, desarrollando tu potencial con ilusión, creando e innovando y aportando desde la digitalización en todos los proyectos a futuro?

La reflexión de estas seis variables es el caldo de cultivo necesario para garantizar qué entiende cada líder por su propio liderazgo y así poderlo compartir con el resto de los líderes de la organización, pues el ejercicio profesional de todos genera, en realidad, la verdadera cultura organizativa.

\section{Conclusiones}

La complejidad actual de los entornos, así como la velocidad de los cambios sociales y organizativos fuerzan a que toda organización esté en continuo cambio y evolución. Asumir este cambio es, en gran parte, el rol del departamento de dirección de personas basada en el talento, que de- 
nominamos gestión del talento. Este rol de agente de cambio es el primer paso para conseguir organizaciones capaces de gestionar el talento desde el modelo 7GT, un modelo integral capaz de gestionar todos estos cambios con agilidad y eficacia. Del mismo modo, las organizaciones se ven inmersas en el reto de un nuevo liderazgo, donde ya no tienen cabida las organizaciones ni muy jerárquicas ni basadas en la supervisión estricta procedente de otras épocas mucho más industriales y menos del conocimiento. La realidad actual implica líderes capaces de gestionar uno a uno a sus colaboradores para obtener lo mejor de cada uno de ellos y sabiendo que ese liderazgo se lo han ganado por el respeto y la equidad en su gestión. El modelo de liderazgo desde el talento con las seis variables guía plantea un nuevo esquema de trabajo a nivel directivo y organizativo.
Ya no basta con hacer bien el trabajo, la palabra clave es la excelencia empresarial capaz de conseguirse desde personas con talento, ágiles en aprendizaje, abiertas de mente y respetuosas de la diversidad y capaces de afrontar los cambios con naturalidad e ilusión. Este gran reto para las organizaciones va a depender de cómo y cuánto trabaje la dirección con sus mandos y coordinadores, pues el verdadero límite de crecimiento y éxito empresarial está en la mente de sus directivos.

\section{Referencias}

Luna, R. (2018). Gestión del talento. De los recursos humanos a la dirección de personas basada en el talento. Editorial Pirámide.

Luna, R. (2021). Liderar desde el talento. Editorial Alienta. 